Journal of Mathematics and Statistics 4 (4): 250-254, 2008

ISSN 1549-3644

(C) 2008 Science Publications

\title{
Numerical Solution of Linear Integro-Differential Equations
}

\author{
${ }^{1}$ Husein Jaradat, ${ }^{2}$ Omar Alsayyed and ${ }^{3} \mathrm{~S}$. Al-Shara' \\ ${ }^{1}$ Department of Mathematics, Al al-Bayt University, Jordan \\ ${ }^{2}$ Department of Mathematics, Al-Zaytoonah University, Jordan \\ ${ }^{3}$ Department of Mathematics, Tafila Technical University, Jordan
}

\begin{abstract}
Problem Statement: Integro-differential equations find special applicability within scientific and mathematical disciplines. In this study, an analytical scheme for solving Integrodifferential equations was presented. Approach: We employed the Homotopy Analysis Method (HAM) to solve linear Fredholm integro-differential equations. Results: Error analysis and illustrative examples were included to demonstrate the validity and applicability of the technique. MATLAB 7 was used to carry out the computations. Conclusion/Recommendations: From now we can use HAM as a novel solver for linear Integro-differential equations.
\end{abstract}

Key words: Homotopy analysis method, integro-differential equations

\section{INTRODUCTION}

In recent years, there has been a growing interest in the Integro-Differential Equations (IDEs) which are a combination of differential and Fredholm-Volterra integral equations. IDEs play an important role in many branches of linear and nonlinear functional analysis and their applications in the theory of engineering, mechanics, physics, chemistry, astronomy, biology, economics, potential theory and electrostatics. The mentioned integro-differential equations are usually difficult to solve analytically; so a numerical method is required. Therefore, many different methods are used to obtain the solution of the linear and nonlinear IDEs such as the successive approximations, Adomian decomposition, Homotopy perturbation method, Chebyshev and Taylor collocation, Haar Wavelet, Tau and Walsh series methods. ${ }^{[1-4,8-16]}$.

In this study, by means of the homotopy analysis method (HAM), presented by Liao ${ }^{[5-7]}$, a general analytic approach is presented to obtain series solutions of linear IDEs:

$y^{\prime}(x)=p(x) y(x)+g(x)+\lambda \int_{a} K(x, t) y(t) d t$

under the initial condition:

$\mathrm{y}(\mathrm{a})=\alpha$

where, the upper limit of the integral is constant or variable, $\lambda, \alpha$, a are constants, $\mathrm{g}(\mathrm{x}), \mathrm{p}(\mathrm{x})$ and $\mathrm{K}(\mathrm{x}, \mathrm{t})$ are given functions, whereas $\mathrm{y}(\mathrm{x})$ is to be determined.
The Homotopy Analysis Method (HAM) is based on homotopy, a fundamental concept in topology and differential geometry. Briefly speaking, by means of the HAM, one constructs a continuous mapping of an initial guess approximation to the exact solution of considered equations. An auxiliary linear operator is chosen to construct such kind of continuous mapping and an auxiliary parameter is used to ensure the convergence of solution series. The method enjoys great freedom in choosing initial approximations and auxiliary linear operators. By means of this kind of freedom, a complicated nonlinear problem can be transferred into an infinite number of simpler, linear sub-problems.

The Homotopy Analysis Method (HAM) is a general analytic approach to solve various types of nonlinear equations, including algebraic equations, ordinary differential equations, partial differential equations, differential-difference equation. More importantly, different from all perturbation and traditional non-perturbation methods, the HAM provides us a simple way to ensure the convergence of solution series and therefore, the HAM is valid even for strongly nonlinear problems.

\section{MATERIALS AND METHODS}

Consider:

$$
\mathrm{N}[\mathrm{y}(\mathrm{x})]=0
$$

Where:

$\mathrm{N}=$ An operator

Corresponding Author: Husein Jaradat, Department of Mathematics, Al al-Bayt University, P.O. Box 130040, Mafraq 25113, Jordan, Tel: +962-0777719675 Fax: +962-6297000 
$\mathrm{y}(\mathrm{x})=$ Unknown function

$\mathrm{x} \quad=$ The independent variable.

Let $\mathrm{y}_{0}(\mathrm{x})$ denote an initial guess of the exact solution $\mathrm{y}(\mathrm{x}), \mathrm{h} \neq 0$ an auxiliary parameter, $\mathrm{H}(\mathrm{x}) \neq 0$ an auxiliary function and $\mathrm{L}$ an auxiliary linear operator with the property $\mathrm{L}[\mathrm{y}(\mathrm{x})]=0$ when $\mathrm{y}(\mathrm{x})=0$. Then using $\mathrm{q} \in[0,1]$ as an embedding parameter, we construct such a homotopy

$$
\begin{aligned}
& \hat{H}\left[\phi(x ; q) ; y_{0}(x), H(x), h, q\right]= \\
& (1-q) L\left[\phi(x ; q)-y_{0}(x)\right]-q h H(x) N[\phi(x ; q)]
\end{aligned}
$$

It should be emphasized that we have great freedom to choose the initial guess $\mathrm{y}_{0}(\mathrm{t})$, the auxiliary linear operator $\mathrm{L}$, the non-zero auxiliary parameter $\mathrm{h}$ and the auxiliary function $\mathrm{H}(\mathrm{t})$.

Enforcing the homotopy (3) to be zero, i.e.:

$$
\hat{H}\left[\phi(x ; q) ; y_{0}(x), H(x), h, q\right]=0
$$

We have the so-called zero-order deformation equation:

$$
(1-q) L\left[\phi(x ; q)-y_{0}(x)\right]=q h H(x) N[\phi(x ; q)]
$$

When $\mathrm{q}=0$, the zero-order deformation Eq. 4 becomes:

$$
\varphi(\mathrm{x} ; 0)=\mathrm{y}_{0}(\mathrm{x})
$$

and when $\mathrm{q}=1$, since $\mathrm{h} \neq 0$ and $\mathrm{H}(\mathrm{t}) \neq 0$, the zero-order deformation Eq. 4 is equivalent to:

$$
\varphi(\mathrm{x} ; 1)=\mathrm{y}(\mathrm{x})
$$

Thus, according to (5) and (6), as the embedding parameter $\mathrm{q}$ increases from 0 to $1, \phi(\mathrm{x} ; \mathrm{q})$ varies continuously from the initial approximation $y_{0}(t)$ to the exact solution $\mathrm{y}(\mathrm{x})$. Such a kind of continuous variation is called deformation in homotopy.

By Taylor's theorem, $\phi(x ; q)$ can be expanded in a power series of $q$ as follows:

$$
\phi(x ; q)=y_{0}(x)+\sum_{m=1}^{\infty} y_{m}(x) q^{m}
$$

Where:

$$
\mathrm{y}_{\mathrm{m}}(\mathrm{x})=\frac{1}{\mathrm{~m} !} \frac{\partial^{\mathrm{m}} \phi(\mathrm{x} ; \mathrm{q})}{\partial \mathrm{q}^{\mathrm{m}}} \mathrm{I}_{\mathrm{q}=0}
$$

If the initial guess $\mathrm{y}_{0}(\mathrm{x})$, the auxiliary linear parameter $\mathrm{L}$, the nonzero auxiliary parameter $\mathrm{h}$ and the auxiliary function $\mathrm{H}(\mathrm{x})$ are properly chosen so that the power series $(7)$ of $\phi(x ; q)$ converges at $q=1$. Then, we have under these assumptions the solution series:

$$
\mathrm{y}(\mathrm{x})=\phi(\mathrm{x} ; 1)=\mathrm{y}_{0}(\mathrm{x})+\sum_{\mathrm{m}=1}^{\infty} \mathrm{y}_{\mathrm{m}}(\mathrm{x})
$$

For brevity, define the vector:

$$
\overrightarrow{\mathrm{y}}_{\mathrm{n}}(\mathrm{x})=\left\{\mathrm{y}_{0}(\mathrm{x}), \mathrm{y}_{1}(\mathrm{x}), \mathrm{y}_{2}(\mathrm{x}), \ldots, \mathrm{y}_{\mathrm{n}}(\mathrm{x})\right\}
$$

According to the definition (7), the governing equation of $\mathrm{y}_{\mathrm{m}}(\mathrm{x})$ can be derived from the zero-order deformation Eq. 4. Differentiating the zero-order deformation Eq. $4 \mathrm{~m}$ times with respective to $\mathrm{q}$ and then dividing by $\mathrm{m}$ ! and finally setting $\mathrm{q}=0$, we have the socalled $\mathrm{m}^{\text {th }}$-order deformation equation:

$$
\mathrm{L}\left[\mathrm{y}_{\mathrm{m}}(\mathrm{x})-\chi_{\mathrm{m}} \mathrm{y}_{\mathrm{m}-1}(\mathrm{x})\right]=\mathrm{hH}(\mathrm{x}) \Re_{\mathrm{m}}\left(\overrightarrow{\mathrm{y}}_{\mathrm{m}-1}(\mathrm{x})\right)
$$

where

$\Re_{m}\left(\vec{y}_{m-1}(x)\right)=\left.\frac{1}{(m-1) !} \frac{\partial^{m-1} N[\phi(x ; q)]}{\partial q^{m-1}}\right|_{q=0}$

and

$$
\chi_{\mathrm{m}}= \begin{cases}0, & \mathrm{~m} \leq 1 \\ 1, & \mathrm{~m}>1\end{cases}
$$

Note that the high-order deformation Eq. 10 is governing by the linear operator $\mathrm{L}$ and the term $\Re_{\mathrm{m}}\left(\overrightarrow{\mathrm{y}}_{\mathrm{m}-1}(\mathrm{x})\right)$ can be expressed simply by (11) for any nonlinear operator $\mathrm{N}$.

According to the definition (11), the right-hand side of equation (10) is only dependent upon $\mathrm{y}_{\mathrm{m}-1}(\mathrm{x})$. Thus, we gain $\mathrm{y}_{1}(\mathrm{x}), \mathrm{y}_{2}(\mathrm{x}) \ldots$ by mean of solving the linear high-order deformation Eq. 10 one after the other in order.

\section{RESULTS}

We are now ready to construct a series solution corresponding to the IDE (1a)(1b). For this purpose, let:

$$
N[y(x)]=y^{\prime}(x)-p(x) y(x)-g(x)-\lambda \int_{a} K(x, t) y(t) d t
$$



reads:

The corresponding $\mathrm{m}^{\text {th }}$-order deformation Eq. 11

$$
\begin{gathered}
\mathrm{L}\left[\mathrm{y}_{\mathrm{m}}(\mathrm{x})-\chi_{\mathrm{m}} \mathrm{y}_{\mathrm{m}-1}(\mathrm{x})\right]=\mathrm{hH}(\mathrm{x}) \Re_{\mathrm{m}}\left(\overrightarrow{\mathrm{y}}_{\mathrm{m}-1}(\mathrm{x})\right), \\
\mathrm{y}_{\mathrm{m}}(0)=0
\end{gathered}
$$

One has:

$$
\begin{aligned}
\Re_{\mathrm{m}}\left(\vec{y}_{\mathrm{m}-1}(\mathrm{x})\right)= & \mathrm{y}_{\mathrm{m}-1}^{\prime}(\mathrm{x})-\mathrm{p}(\mathrm{x}) \mathrm{y}_{\mathrm{m}-1}(\mathrm{x}) \\
& -\left(1-\chi_{\mathrm{m}}\right) \mathrm{g}(\mathrm{x})-\lambda \int_{\mathrm{a}} \mathrm{K}(\mathrm{x}, \mathrm{t}) \mathrm{y}_{\mathrm{m}-1}(\mathrm{t}) \mathrm{dt}
\end{aligned}
$$

The corresponding homotopy-series solution is given by:

$$
\mathrm{y}(\mathrm{x})=\mathrm{y}_{0}(\mathrm{x})+\sum_{\mathrm{m}=1}^{\infty} \mathrm{y}_{\mathrm{m}}(\mathrm{x})
$$

It is worth to present a simple iterative scheme for $y_{m}(x)$ To this end, the linear operator $L$ is chosen to be $L[y(x)]=\frac{d y}{d x}$, as an initial guess $y_{0}(x)=\alpha$ is taken, a nonzero auxiliary parameter $\mathrm{h}=-1$ and an auxiliary function $\mathrm{H}(\mathrm{x})=1$ are taken. This is substituted into (13) to give the recurrence relation:

$$
\begin{gathered}
\mathrm{y}_{0}(\mathrm{x})=\alpha, \\
\mathrm{y}_{1}(\mathrm{x})=\int_{0}^{\mathrm{x}}\left(\alpha \mathrm{p}(\tau)+\mathrm{g}(\tau)+\lambda \alpha \int_{\mathrm{a}} \mathrm{K}(\tau, \mathrm{t}) \mathrm{dt}\right) \mathrm{d} \tau
\end{gathered}
$$

and for $\mathrm{m} \geq 1$ :

$$
y_{m}(x)=\int_{0}^{x}\left(p(\tau) y_{m-1}(x)+\lambda \int_{a} K(\tau, t) y_{m-1}(t) d t\right) d \tau
$$

It is important to show that the homotopy-series solution (14) converges to the solution of the IDE (1a)(1b). To this end, we have the following theorem.

Theorem 1: As long as the series (14) converges, it must be the exact solution of the integral equation (1a)(1b).

Proof: If the series (14) converges, we can write:

$$
\mathrm{S}(\mathrm{x})=\sum_{\mathrm{m}=0}^{\infty} \mathrm{y}_{\mathrm{m}}(\mathrm{x})
$$

And it holds that: $\lim _{\mathrm{m} \rightarrow \infty} \mathrm{y}_{\mathrm{m}}(\mathrm{x})=0$

We can verify that:

$\sum_{m=1}^{n}\left[y_{m}(x)-\chi_{m} y_{m-1}(x)\right]=y_{n}(x)$

which gives us, according to (16):

$$
\sum_{m=1}^{\infty}\left[y_{m}(x)-\chi_{m} y_{m-1}(x)\right]=\lim _{n \rightarrow \infty} y_{n}(x)=0
$$

Furthermore, using (17) and the definition of the linear operator L, we have:

$$
\sum_{m=1}^{\infty} L\left[y_{m}(x)-\chi_{m} y_{m-1}(x)\right]=L \sum_{m=1}^{\infty}\left[y_{m}(x)-\chi_{m} y_{m-1}(x)\right]=0
$$

In this line, we can obtain that:

$$
\sum_{\mathrm{m}=1}^{\infty} \mathrm{L}\left[\mathrm{y}_{\mathrm{m}}(\mathrm{x})-\chi_{\mathrm{m}} \mathrm{y}_{\mathrm{m}-1}(\mathrm{x})\right]=\mathrm{hH}(\mathrm{x}) \sum_{\mathrm{m}=1}^{\infty} \Re_{\mathrm{m}-1}\left(\overrightarrow{\mathrm{y}}_{\mathrm{m}-1}(\mathrm{x})\right)
$$

which gives, since $\mathrm{h} \neq 0$ and $\mathrm{H}(\mathrm{x}) \neq 0$, that:

$\sum_{\mathrm{m}=1}^{\infty} \Re_{\mathrm{m}-1}\left(\overrightarrow{\mathrm{y}}_{\mathrm{m}-1}(\mathrm{x})\right)=0$

Substituting $\sum_{\mathrm{m}=1}^{\infty} \Re_{\mathrm{m}-1}\left(\overrightarrow{\mathrm{y}}_{\mathrm{m}-1}(\mathrm{x})\right)$ into the expression and simplifying it, we have:

$$
\begin{aligned}
& \sum_{\mathrm{m}=1}^{\infty} \mathfrak{R}_{\mathrm{m}-1}\left(\vec{y}_{\mathrm{m}-1}(\mathrm{x})\right)=\sum_{\mathrm{m}=1}^{\infty}\left[\mathrm{y}_{\mathrm{m}-1}^{\prime}(\mathrm{x})-\mathrm{p}(\mathrm{x}) \mathrm{y}_{\mathrm{m}-1}(\mathrm{x})-\right. \\
& \left.\left(1-\chi_{\mathrm{m}}\right) \mathrm{g}(\mathrm{x})-\lambda \int_{\mathrm{a}} \mathrm{K}(\mathrm{x}, \mathrm{t}) \mathrm{y}_{\mathrm{m}-1}(\mathrm{t}) \mathrm{dt}\right] \\
& \left.=\sum_{\mathrm{m}=0}^{\infty} \mathrm{y}_{\mathrm{m}}^{\prime}(\mathrm{x})-\mathrm{p}(\mathrm{x}) \sum_{\mathrm{m}=0}^{\infty} \mathrm{y}_{\mathrm{m}}(\mathrm{x})-\mathrm{g}(\mathrm{x})-\lambda \int_{\mathrm{a}} \mathrm{K}(\mathrm{x}, \mathrm{t}) \sum_{\mathrm{m}=0}^{\infty} \mathrm{y}_{\mathrm{m}}(\mathrm{t}) \mathrm{dt}\right] \\
& =\mathrm{S}^{\prime}(\mathrm{x})-\mathrm{p}(\mathrm{x}) \mathrm{S}(\mathrm{x})-\mathrm{g}(\mathrm{x})-\lambda \int_{\mathrm{a}} \mathrm{K}(\mathrm{x}, \mathrm{t}) \mathrm{S}(\mathrm{t}) \mathrm{dt}
\end{aligned}
$$

From (18) and (19), we have:

$$
S^{\prime}(x)=p(x) S(x)+g(x)+\lambda \int_{a} K(x, t) S(t) d t
$$

and so, $\mathrm{S}(\mathrm{x})$ must be the exact solution of the IDE (1a)(1b). 


\section{DISCUSSION}

The HAM provides an analytical solution in terms of an infinite power series. However, there is a practical need to evaluate this solution. The consequent series truncation and the practical procedure conducted to accomplish this task, together transforms the analytical results into an exact solution, which is evaluated to a finite degree of accuracy. In order to investigate the accuracy of the HAM solution with a finite number of terms, three examples will be solved.

To show the efficiency of the present method for our problem in comparison with the exact solution we report absolute error which is defined by:

$$
\left|\mathrm{Ey}_{\mathrm{HAM}}^{\mathrm{N}}\right|=\left|\mathrm{y}_{\text {exact }}-\mathrm{y}_{\mathrm{HAM}}^{\mathrm{N}}\right|
$$

where, $\mathrm{y}_{\mathrm{HAM}}^{\mathrm{N}}=\sum_{\mathrm{m}=0}^{\mathrm{N}} \mathrm{y}_{\mathrm{m}}(\mathrm{x})$. MATLAB 7 is used to carry out the computations.

Example 1: First we consider the integro-differential equation:

$$
y^{\prime}(x)=3 e^{3 x}-\frac{1}{3}\left(2 e^{3}+1\right) x+\int_{0}^{1} 3 x t y(t) d t, y(0)=1
$$

For which the exact solution is $y(x)=e^{3 x}$. We begin with $\mathrm{y}_{0}(\mathrm{x})=1$, its iteration formulation reads:

$$
\begin{aligned}
& y_{1}(x)=\int_{0}^{x}\left(3 e^{3 \tau}-\frac{1}{3}\left(2 e^{3}+1\right) \tau+\int_{0}^{1} 3 \tau t d t\right) d \tau \\
& y_{m}(x)=\int_{0}^{x}\left(\int_{0}^{1} 3 \tau t y_{m-1}(t) d t\right) d \tau, \quad m=2,3, \ldots
\end{aligned}
$$

Some numerical results of these solutions are shown in Table 1. The tabulated results indicate that as $\mathrm{N}$ increases the errors are decreased more rapidly.

Example 2: Consider the FIDE:

$$
y^{\prime}(x)=y(x)-\frac{1}{2} x+\frac{1}{1+x}-\ln (1+x)+\frac{1}{(\ln 2)^{2}} \int_{0}^{1} \frac{x}{1+t} y(t) d t, y(0)=0
$$

For which the exact solution is $y(x)=1 n(1+x)$. We begin with $\mathrm{y}_{0}(\mathrm{x})=0$, its iteration formulation reads:

$$
\mathrm{y}_{1}(\mathrm{x})=\int_{0}^{\mathrm{x}}\left(-\frac{1}{2} \tau+\frac{1}{1+\tau}+\ln (1+\tau)\right) \mathrm{d} \tau
$$

and for $\mathrm{m}=2,3, \ldots$

$$
\mathrm{y}_{\mathrm{m}}(\mathrm{x})=\int_{0}^{\mathrm{x}} \mathrm{y}_{\mathrm{m}-1}(\tau)+\left(\frac{1}{(\ln 2)^{2}} \int_{0}^{1} \frac{\tau}{1+\mathrm{t}} \mathrm{y}_{\mathrm{m}-1}(\mathrm{t}) \mathrm{dt}\right) \mathrm{d} \tau
$$

Table 1: Numerical results of example 1

\begin{tabular}{llll}
\hline $\mathrm{x}_{\mathrm{i}}$ & $\left|\mathrm{Ey}_{\text {HАM }}^{10}\right|$ & $\left|\mathrm{Ey}_{\text {HАM }}^{20}\right|$ & $\left|\mathrm{Ey}_{\text {HАM }}^{30}\right|$ \\
\hline 0.0 & 0 & 0 & 0 \\
0.2 & $9.56054 \mathrm{E}-5$ & $5.25769 \mathrm{E}-9$ & $2.92 \mathrm{E}-13$ \\
0.4 & $3.82421 \mathrm{E}-4$ & $2.10307 \mathrm{E}-8$ & $1.16 \mathrm{E}-12$ \\
0.6 & $8.60448 \mathrm{E}-4$ & $4.73192 \mathrm{E}-8$ & $2.61 \mathrm{E}-12$ \\
0.8 & $1.52968 \mathrm{E}-3$ & $8.41230 \mathrm{E}-8$ & $4.63 \mathrm{E}-12$ \\
1.0 & $2.39013 \mathrm{E}-3$ & $1.31442 \mathrm{E}-7$ & $7.23 \mathrm{E}-12$ \\
\hline
\end{tabular}

Table 2: Numerical results of example 2

\begin{tabular}{llll}
\hline $\mathrm{x}_{\mathrm{I}}$ & $\left|\mathrm{Ey}_{\text {HАM }}^{10}\right|$ & $\left|\mathrm{Ey}_{\text {HАM }}^{15}\right|$ & $\left|\mathrm{Ey}_{\text {HAM }}^{20}\right|$ \\
\hline 0.0 & 0 & 0 & 0 \\
0.2 & $1.37293 \mathrm{E}-5$ & $1.59052 \mathrm{E}-7$ & $1.09615 \mathrm{E}-8$ \\
0.4 & $6.59695 \mathrm{E}-5$ & $7.64242 \mathrm{E}-7$ & $5.26700 \mathrm{E}-8$ \\
0.6 & $1.80934 \mathrm{E}-4$ & $2.09607 \mathrm{E}-6$ & $1.44457 \mathrm{E}-7$ \\
0.8 & $3.98060 \mathrm{E}-4$ & $4.61144 \mathrm{E}-6$ & $3.17811 \mathrm{E}-7$ \\
1.0 & $7.81579 \mathrm{E}-4$ & $9.05447 \mathrm{E}-6$ & $6.24015 \mathrm{E}-7$ \\
\hline
\end{tabular}

Table 3: Numerical results of example 3

\begin{tabular}{llll}
\hline $\mathrm{x}_{\mathrm{i}}$ & $\left|\mathrm{Ey}_{\text {НАM }}^{10}\right|$ & $\left|\mathrm{Ey}_{\text {HАM }}^{20}\right|$ & $\left|\mathrm{Ey}_{\text {HАM }}^{30}\right|$ \\
\hline 0.0 & 0 & 0 & 0 \\
0.2 & $2.5701 \mathrm{E}-4$ & $4.2117 \mathrm{E}-6$ & $3.1192 \mathrm{E}-10$ \\
0.4 & $4.8001 \mathrm{E}-4$ & $5.6797 \mathrm{E}-7$ & $2.5436 \mathrm{E}-11$ \\
0.6 & $7.6043 \mathrm{E}-4$ & $4.2112 \mathrm{E}-8$ & $6.6122 \mathrm{E}-11$ \\
0.8 & $9.7723 \mathrm{E}-3$ & $6.4123 \mathrm{E}-8$ & $8.2163 \mathrm{E}-12$ \\
1.0 & $1.3021 \mathrm{E}-3$ & $2.2314 \mathrm{E}-6$ & $1.5723 \mathrm{E}-09$ \\
\hline
\end{tabular}

Some numerical results of these solutions are shown in Table 2. Results indicate that the convergence rate is very fast and lower approximations can achieve high accuracy.

Example 3: In the last example, we Consider the FIDE:

$$
\begin{aligned}
y^{\prime}(x) & =y(x)-\cos (2 \pi x)-2 \pi \sin (2 \pi x)-\frac{1}{2} \sin (4 \pi x) \\
& +\int_{0}^{1} \sin (4 \pi x+2 \pi t) y(t) d t, y(0)=1
\end{aligned}
$$

For which the exact solution is $y(x)=\cos (2 \pi x)$. We begin with $\mathrm{y}_{0}(\mathrm{x})=1$, its iteration formulation reads:

$$
\begin{aligned}
\mathrm{y}_{1}(\mathrm{x})= & \int_{0}^{\mathrm{x}} \cdot\left(1-\cos (2 \pi \tau)-2 \pi \sin (2 \pi \tau)-\frac{1}{2} \sin (4 \pi \tau)+\right. \\
& \int_{0}^{1}\left(\sin (4 \pi \tau+2 \pi \mathrm{t}) \mathrm{y}_{\mathrm{m}-1}(\mathrm{t}) \mathrm{dt}\right) \mathrm{d} \tau,
\end{aligned}
$$

and for $\mathrm{m}=2,3, \ldots$

$$
y_{m}(x)=\int_{0}^{x}\left(y_{m-1}(\tau)+\int_{0}^{1}\left(\sin (4 \pi \tau+2 \pi t) y_{m-1}(t) d t\right)\right) d \tau
$$

Some numerical results of these solutions are shown in Table 3. 


\section{CONCLUSION}

The HAM was used for evaluating integrals arises in integral transforms. Three examples were discussed as demonstrations. It was concluded that the homotopy methodology is very powerful and efficient technique in evaluating a wide class of integral transforms and problems. It is also worth noting to point out that the advantage of the homotopy methodology is the fast convergence of the solutions.

\section{REFERENCES}

1. Asady, B. and M.T. Kajani, 2005. Direct method for solving integro differential equations using hybrid Fourier and block-pulse functions. Int. J. Comput. Math., 82: 889-895. DOI: $10.1080 / 00207160412331336044$.

2. Danfu, H. and S. Xufeng, 2007. Numerical solution of integro-differential equations by using CAS wavelet operational matrix of integration. Applied Math. Comput., 194: 460-466.

DOI: 10.1016/j.amc.2007.04.048.

3. Golbabai, A. and M. Javidi, 2007. Application of He's homotopy perturbation method for nth-order integro-differential equations. Applied Math. Comput., 190: 1409-1416.

DOI: 10.1016/j.amc.2007.02.018.

4. Karamete, A. and M. Sezer, 2002. A Taylor collocation method for the solution of linear integro-differential equations. Int. J. Comput. Math., 79: 987-1000.

DOI: $10.1080 / 00207160212116$.

5. Liao, S.J., 2003. An explicit analytic solution to the Thomas-Fermi equation. Applied Math. Comput., 144: 495-506.

DOI: 10.1016/S0096-3003(02)00423-X.

6. Liao, S.J., 2003. Beyond Perturbation: Introduction to the Homotopy Analysis Method. 1st Edn. Chapman and Hall/CRC Press Publisher, Boca Raton, pp: 336. ISBN-10: 158488407X.

7. Liao, S.J., 2004. On the homotopy analysis method for nonlinear problems. Applied Math. Comput., 147: 499-513.

DOI: 10.1016/S0096-3003(02)00790-7.
8. Maleknejad, K. and F. Mirzaee, 2006. Numerical solution of integro-differential equations by using rationalized Haar functions method, Kybernetes. Int. J. Syst. Math., 35:1735-1744. DOI: 10.1108/03684920610688694.

9. Pour-Mahmoud, J., M.Y. Rahimi-Ardabili and S. Shahmorad, 2005. Numerical solution of the system of Fredholm integro-differential equations by the tau method. Applied Math. Comput., 168: 465-478. DOI: 10.1016/j.amc.2004.09.026.

10. Rashed, M.T., 2004. Numerical solution of functional differential, integral and integrodifferential equations. Applied Numeric. Math., 156: 485-492. DOI: 10.1016/j.amc.2003.08.021.

11. Rahimi-Ardabili, M.Y. and Shahmorad, S., 2007. Iterative numerical solution of non-linear integrodifferential equations by the Tau method. Applied Math. Comput., 193: 514-522.

DOI: 10.1016/j.amc.2007.04.002.

12. Razzaghi, M. and S. Yousefi, 2005. Legendre wavelets method for the nonlinear Volterra Fredholm integral equations. Math. Comput. Simul., 70: 1-8. DOI: 10.1016/j.matcom.2005.02.035.

13. Tavassoli Kajani, M., M. Ghasemi and E. Babolian, 2006. Numerical solution of linear integro-differential equation by using sine--cosine wavelets. Applied Math. Comput., 180: 569-574. DOI: 10.1016/j.amc.2005.12.044.

14. Wang, W., 2006. An algorithm for solving the higher-order nonlinear Volterra-Fredholm integrodifferential equation with mechanization. Applied Math. Comput., 172: 1-23.

DOI: 10.1016/j.amc.2005.01.116.

15. Wang, S. and J. He, 2007. Variational iteration method for solving integro-differential equations. Phys. Lett. A, 367: 188-191. DOI: $10.1016 /$ j.physleta.2007.02.049.

16. Zhao, J. and R.M. Corless, 2006. Compact finite difference method for integro-differential equations. Applied Math. Comput., 177: 271-288. DOI: 10.1016/j.amc.2005.11.007. 